\title{
Sustainability issues in low-middle income apartments in urban Amman, Jordan: heating devices and health concerns
}

\author{
A. Younis ${ }^{1}$, A. Taki $^{1} \&$ S. Bhattacharyya ${ }^{2}$ \\ ${ }^{1}$ Leicester School of Architecture, De Montfort University, UK \\ ${ }^{2}$ School of Engineering and Sustainable Development, \\ De Montfort University, UK
}

\begin{abstract}
Energy security constitutes a major challenge for sustainable development of the Kingdom of Jordan. This has led the Ministry of Energy and Mineral Resources to integrate a comprehensive energy master plan for to develop the energy sector by 2029 . Of the total residential energy consumption, 61 percent is consumed for heating spaces. Greenhouse gas (GHG) emissions produced by domestic stock in Jordan are anticipated to increase by 59 percent in 2018. Most households heat their houses using traditional devices such as portable unflued kerosene and liquefied petroleum gas (LPG) stoves. Combustion of such heaters generates toxic by-products causing symptoms and illness among residents as a result of poor indoor air quality. This paper discusses these issues in view of urban low-middle income apartments in the capital Amman, with a focus on investigating the types of stoves used and health implications associated with using them. A representative sample of 106 low-middle income households in urban Amman were surveyed, through semi-structured interviews, to explore how they responded to the environmental conditions. Results showed that unflued kerosene and LPG stoves were used for heating spaces by around 39 percent and 89 percent of the total households surveyed, respectively. It was also found that almost 65 percent of them used more than one device for heating their apartments. Furthermore, around 50 percent of those households reported different health problems related to asthma which could partially be due to the use of these heating devices. The field study also showed that almost 75 percent of households lived in apartments constructed with external envelopes of hollow cement blocks leading to poorer fabric performance. The paper concludes with calling for thrift retrofit
\end{abstract}


interventions for existing low-middle income apartments and raising inhabitants' awareness towards the proper use of stoves. This would enhance their thermal comfort, reduce carbon emissions and help improve residents' quality of life, which eventually would contribute to ameliorating related health issues.

Keywords: sustainable development, urban Amman, low-middle income apartments, energy, GHG emissions, unflued stoves, health issues, retrofit.

\section{Introduction}

Energy security is a major challenge to the sustainable development of Jordan. This has stimulated Ministry of Energy and Mineral Resources (MEMR) to develop and integrate a comprehensive master plan for energy - approved by the Council of Ministers in 2004 - aiming towards developing energy by 2029 [1]. Alkurdi et al. [2] even went further to describe the problem of energy in Jordan as "chronic", attributing this to the lack of natural energy resources in the kingdom and its dependence on importation to cover most of its energy needs, which makes energy sector vulnerable to international energy prices [2]. As a result, the everescalating trend of fuel prices in Jordan has negatively affected the low-income class of the society [3]. Moreover, the dominant thermal load at residential stock in the country is heating, as around 61 percent of energy consumed by this sector is consumed for heating spaces $[4,5]$. Heating also represents around 14 percent of total national energy demands [4].

Most households in Jordan still heat their houses using traditional unflued kerosene and LPG heaters in addition to fixed flued stoves [4], which - according to Jaber [6] - produces indoor pollutants and emits $\mathrm{CO}_{2}$ to the atmosphere. For example, the combustion of kerosene fuel causes serious health and environmental hazards [6]. Yet, large number of dwellings in Jordan experience significant amounts of energy losses [7]. This could be attributed to the claim stated by Johansson et al. [8] on the lack of well-adapted buildings constructed in recent decades in Jordan, which makes them more vulnerable to greater energy consumption for cooling and heating purposes.

Accordingly, by 2018 greenhouse gas (GHG) emissions produced by residential stock in the kingdom are expected to jump by 59 percent, based on 2008 levels [7]. Hence, this paper describes the different types of heating devices used in low-middle income apartments in urban Amman - based on the reviewed literature and the conducted survey - and highlights their health risks.

\section{Background}

\subsection{Jordan: an overview}

The Kingdom of Jordan is an "upper-middle income country" [9], highly urbanised [1] with the highest of around 38.7 percent of its $6,530 \times 10^{3}$ estimated population lives in the capital Amman [10], the "economic and industrial hub" of the country [11]. 
According to data derived from Department of Statistics in Jordan (DoS) by Younis et al. [12], Jordanian society could be divided into four categories, namely: below poverty, below-middle income, middle income and affluent classes, as the first two classes form the low-income group. The same researchers also found in their study that low-middle income households - which constitute around 74 percent of total urban households in the capital Amman - seem to be vulnerable in the face of the present energy crisis [12].

Energy in Jordan has been described as a "chronic problem" due to the kingdom's lack of natural resources [2], as around 95 percent of its energy needs are imported [13]. Around 30 percent of total energy consumed in 2009 was attributed to the residential stock [13], with round 61 percent of total consumption in Jordanian houses is attributed to heating spaces [4, 5]. Moreover, in their study, Al-Ghandoor et al. [7] have concluded that demands on fuels and electricity are anticipated to surge by 23 percent and 100 percent, respectively by 2018 , which would consequently lead to a 59 percent jump in GHG emitted by the residential stock in the same year, stimulating application of robust energy conservation measures as urgently needed. The researchers considered the population variable in their empirical models due to the positive correlation between population growth and the energy demand of residential sector [7].

Large amounts of Jordan's financial resources have been invested in the construction industry [8]. According to a government report, around 32,000 dwellings are demanded yearly, divided between two needs: new construction and upgrade of existing units [1]. Moreover, according to a report on "Jordan Poverty Reduction Strategy", apartments form 73 percent of the housing stock in the country, which constitutes more than 80 percent of total buildings across all Jordanian cities [1]. However, energy efficiency of houses in Jordan is substantially affected by significant energy losses [7], given that the buildings erected in the last decades in Jordan are claimed to be "not well adapted to the climate", which would imply the need for more cooling and heating loads [8]. Furthermore, according to Jaber [6], only 5 percent of residential stock has wall insulation.

Given the above discussions, it is worth highlighting the heating devices used by the vulnerable classes of the society, namely low-middle income groups and health hazards implications associated with their use. The following section will discuss those two issues.

\subsection{Heating devices used and their health implications}

\subsubsection{Overview}

Heating water and spaces in Jordanian dwellings is mainly dependent on combustion of fossil fuels $[4,6]$, as kerosene and LPG were found to be the most dominant and popular fuels used for these purposes [4, 6, 14], which would have significant $\mathrm{CO}_{2}$ pollution implications $[4,6]$. Portable heaters are the most commonly used devices across households, particularly by low-income classes [4], to cut heating energy costs [6]. For example, an analysis of the household surveys for the years 2006, 2008 and 2010, reveals that kerosene/diesel and LPG heaters were the dominant types used by low-middle income households in urban 
Amman over these periods [12]. Younis et al. [12] also continued to establish that these households constituted around 87 percent of total households in urban areas of the capital, who used kerosene for heating their apartments [12]. Jaber et al. [4] claimed that reliance of poor households on using kerosene for heating purposes comes from their use of cheap kerosene based heaters which could simultaneously be utilised both for space heating and cooking. This type of dual usage, claimed for the kerosene based heater, has also been reported as the case for LPG based heaters [15]. Moreover, households in Jordan tend to use small kerosene or LPG heaters as back-up for each other, or when central heating is turned off $[4,6]$. This could be attributed to the fact that in an attempt to save on heating costs inhabitants prefer to use small heaters to central heating.

Yet, due to the energy readjustment programme launched in 1993 and the lifting of government fuel subsidies, kerosene prices increased and soon reflected their real economic cost. This led people to depend on LPG fuels for heating purposes $[4,6,15]$. The widespread usage of LPG in Jordan is also attributed to the cleaner and more reliable nature of LPG as compared to kerosene [4], which was eliminated from the petroleum subsidies $[4,16]$. For example, according to KAP Household-Baseline Survey conducted in Jordan over the 12 governorates with sample size of 1000 respondents, 68 percent and 54 percent of households were found using LPG and kerosene fuels, respectively for heating spaces with very few of 7 percent and 13 percent used central heating and electrical heaters, respectively for the same purpose $[14,17]$.

Accordingly, it could be claimed that the dwellings in Jordan, especially of low-middle income classes, were subject to a number of pollutants and health hazards, given the dominant types of heating devices used for heating spaces and water for domestic hot water (DHW) purposes, as well as the way the inhabitants used to utilise them. Hence, the following section will be discussing associative health hazards of the issue.

\subsubsection{Health hazards}

Design of the indoor environment should provide basic human requirements of healthy and comfortable interior spaces without compromise on low energy consumption [18]. Yet, for example, there is a noteworthy gap in the information necessary to draw conclusions on the environmental and health impacts of kerosene and/or portable heating appliances used in Jordan [19]. Combustion of fossil fuels, on which residential sector in Jordan depend heavily, is a significant contributor to air pollution and building up carbon dioxide $\left(\mathrm{CO}_{2}\right)$ in the atmosphere [4]. Further, combustion of unflued devices used for heating spaces emits high levels of toxic by-products, such as carbon monoxide (CO), that often exceed accepted ones which eventually result in poor indoor quality of living [4, 6]. Al Momani and Ali [20] claimed that 80 percent or more of occupants should feel satisfied and suffer no harmful effects. For example, according to Bierwirth [21], at levels above 800 parts per million (ppm) of $\mathrm{CO}_{2}$, occupants of an indoor environment would be vulnerable to different symptoms, such as respiratory illnesses, headaches and fatigue. 
Moreover, combustion of kerosene produces a mixture of pollutants that significantly affects indoor quality of houses, especially poorly ventilated ones. Such pollutants involve CO, sulphur oxides, polycyclic aromatic hydrocarbons (which are extremely carcinogenic) and nitrogen oxides, to name a few [19]. Locally produced kerosene and diesel has a sulphur content of 0.2 percent and 1.2 percent by weight by international standards, respectively [19] compared to the maximum allowed contents of 0.01 percent for kerosene in USA and Japan [15], for instance. The sulphur content of locally manufactured kerosene is relatively high, given its direct combustion through unflued stove inside the dwelling for heating purposes [15]. Comparatively, although LPG fuel is considered to be more efficient and cleaner compared to kerosene, it also has hazards like gas leakage and direct exposure to fire, which (the latter) is a common characteristic with kerosene stoves [4].

Al Momani and Ali [20] have investigated the issue of Sick Building Syndrome (SBS) in their study, which has been conducted across 40 apartments in different cities in Jordan including Amman. Different symptoms were shown to have a temporal correlation with a specific building have been involved in the study. For instance, drowsiness and shortness of breath has been possibly attributed to $\mathrm{CO}_{2}$ emissions while nausea and impaired vision have been potentially associated with $\mathrm{CO}$ pollutant. An interesting finding of Al Momani and Ali [20] study is the significant effect of different variables, such as building envelope and location of the apartment within the building on SBS. The latter point may highly evoke retrofit issues for apartment buildings to contribute in providing healthy environments for their inhabitants. Moreover, reliance on using un-vented stoves should be associated with utilising them for short times in well ventilated spaces and following manufacturers' guides to avoid accumulative exposure of inhabitants to gaseous pollutants [6].

Jaber [6] claimed that there is a negative correlation between the use of kerosene fuel and household's income. This claim may coincide with Shirnding's (1991) claim (as cited in [19]) that the urban poor are vulnerable to exposure to pollutants of high levels by combustion of such fuels inside their dwellings, due to their reliance on grimy and less efficient fuels. The same researcher goes further to report cases of accidents and death, as result of suffocation, or health implications, such as respiratory diseases, which stem from inhabitants' exposure to gaseous pollutants produced by combustion of fuels inside poorly ventilated dwellings while they are sleeping and/or staying in such unhealthy environments. Furthermore, the urban poor usually live in heavily populated areas surrounded by industrial and waste-dumping locations, which should be read as an added burden to their economic status and polluted living conditions [19].

On the other hand, in addition to gaseous pollutants, combustion of kerosene and LPG also produces water vapour which condenses on cold surfaces and results in dampness and fungi areas, particularly in poorly ventilated houses (Jaber et al. as cited in [6]). Around 53 percent of households in Jordan suffer from dampness problems [6] which, according to reports issued by the Ministry of Energy and Mineral Resources in 1997 and the National Electricity Company in 2000 in 
Jordan (as cited in [19]) would provide a healthy environment for mould growth and eventually results in bronchial ramifications.

Hence, the aforementioned discussions stimulate the urgent need to highlight the issue of heating devices used in Jordan, especially urban Amman, and their health implications. It could be inferred also that the urban poor were found as the most vulnerable to such scenarios.

\section{Research methodology}

In the winter season of 2015, a survey was conducted with a representative sample of 106 households across the five sub-districts of urban Amman, namely Marka, Qasabat Amman, Al-Queisma, Al-Jama'a and Wadi Al-Seir. The survey aimed at exploring thermal comfort and energy efficiency issues in these apparently vulnerable groups. The interviewees were asked a series of questions related to household and apartment characteristics, types of heating stoves used inside the apartment and their behaviour in this regard, fuel expenditures, their thermal comfort, for example. Some photographs were taken inside and outside some visited apartments to support some research claims. QSR NVivo 10 and Microsoft Excel 2010 were used for analysing the collected data.

\section{Results and discussions}

From the analysis of the surveys, we can derive four main conclusions concerning the use of heating devices and their consequences on the health. Firstly, it has been found that around 38.7 percent and 88.7 percent of surveyed households used kerosene and LPG stoves, respectively to heat their apartments (see Figures 1-3 below). Almost 51.2 percent and 53.2 percent from those were low-income households (below-poverty and below-middle classes) who also used kerosene and LPG, respectively for the same purpose. This finding of households' greater tendency towards using LPG stoves over others also agrees with the results of the KAP Household-Baseline Survey discussed above. Also, the noticeable difference between users of kerosene and LPG stoves may be attributed (as discussed above) to the jump of kerosene prices after lifting the subsidy which was applied on it and the consideration of users for LPG stoves as cleaner than kerosene ones. Hence, more studies with a larger sample size are recommended to further investigate this issue.

Secondly, the figures also clearly show that the dominant types of stoves used by the surveyed low and middle income households were kerosene and LPG stoves. However, the survey also revealed that 65.1 percent of total households used more than one heating device inside the apartment as a back-up. This point would agree with the findings of Jaber et al. [4] and Jaber [6] aforementioned. The graphs further illustrate that unflued kerosene and LPG heaters were common among the back-up stoves used. In their study, Johansson et al. [8] found that the average measured ventilation rate in an apartment in Amman was as low as 0.3ach $+/-13$ percent in winter, compared to $2.38 \mathrm{ach}+/-13$ percent in summer. Moreover, interviewees reported various domestic accidents caused by heating stoves 


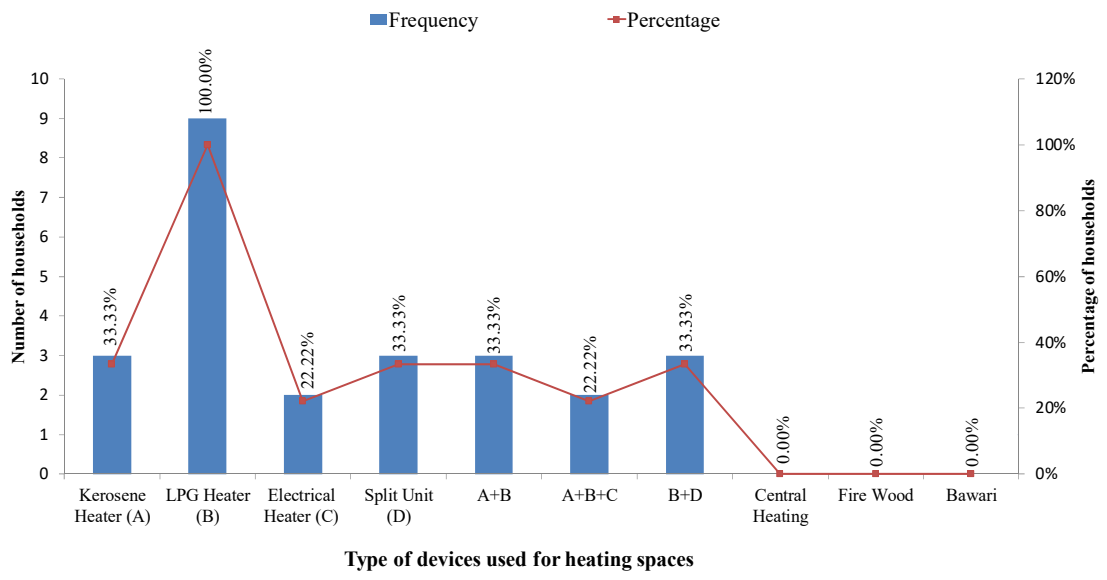

Figure 1: Types of heating devices used by surveyed below poverty households. (Source: Younis, 2015, unpublished.)

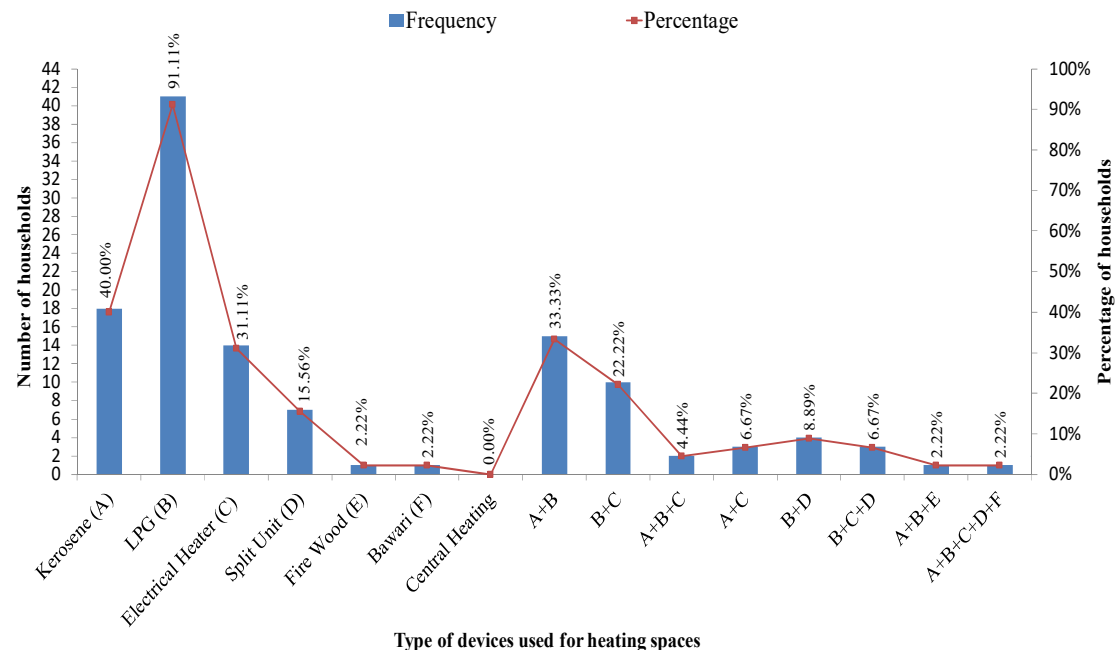

Figure 2: Types of heating devices used by surveyed below-middle income households. (Source: Younis, 2015, unpublished.) 


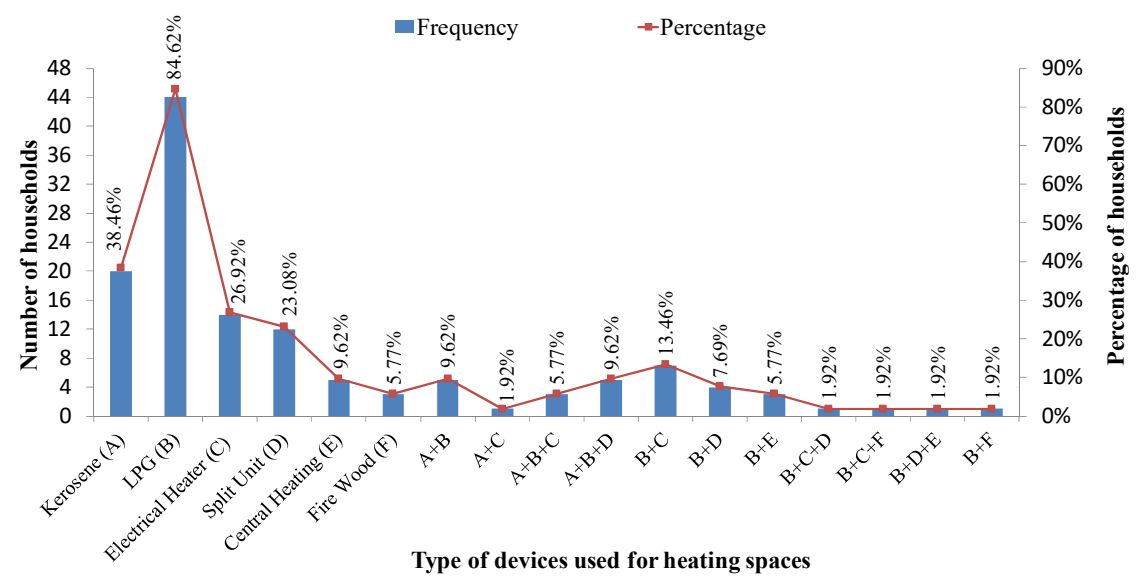

Figure 3: Types of heating devices used by surveyed middle income households.

occurred in homes in Jordan. For example, various fatalities were reported which occurred when the inhabitants used the stoves inside the bathroom with the window closed, or when they left them on while they were sleeping, a hazard point that meets with Shirnding's point [19] discussed in Section 2.2.2. This, when taken in parallel with the related discussions in Section 2, may worsen the situation and increase health hazards inside such poorly ventilated houses.

Thirdly, results show that around 50 percent of surveyed low and middle income households suffered from health problems and/or safety issues which were associated with different types of devices used for heating water (for DHW purposes) and spaces. Almost 54.7 percent represented low income households who reported such problems. Further, around 23.6 percent of the surveyed households complained about/of the existence of fungi inside their apartments, as 56 percent of those were the low-income class. Consequently, one of the interviewees became an asthmatic due to the mould growth inside their house, for instance. Many of the respondents tried to eliminate such detrimental health effects by cladding the affected walls with "Japanese Plaster" or "Moral" (called locally: teena yabaneyya) - see Figure 4 - ceramic tiles, gypsum boards or even by repainting the wall. The choice of different techniques to overcome these problems seemed to depend on the economic status of the household. However, the material (shown in Figure 5) was spoiled by rain water penetrating through the leaky window of this apartment. Also, according to the householder, the material didn't prove to be as thermally efficient as was recommended to him. This may reflect the poor insulation this household had in their apartment. Some households also preferred to keep windows and doors closed while heaters were running inside the room they used to gather in. These actions, undertaken to keep the heat in, can pose serious health risks. Occasionally, these devices have even caused serious accidents to different households, namely scalds, malformation and suffocation, for example. 
Lastly, households were also asked about construction materials of their apartments' insulation. Surprisingly, it was found that around 74.5 percent of total surveyed apartments had an envelope of two layers of $2.5 \mathrm{~cm}$ cement plaster (inside and outside the apartment) with an in-between $15 \mathrm{~cm}$ thick concrete hollow brick. Further, almost 78.5 percent of those had only this type of construction (not mixed with other types) for the entire external envelopes of the houses.

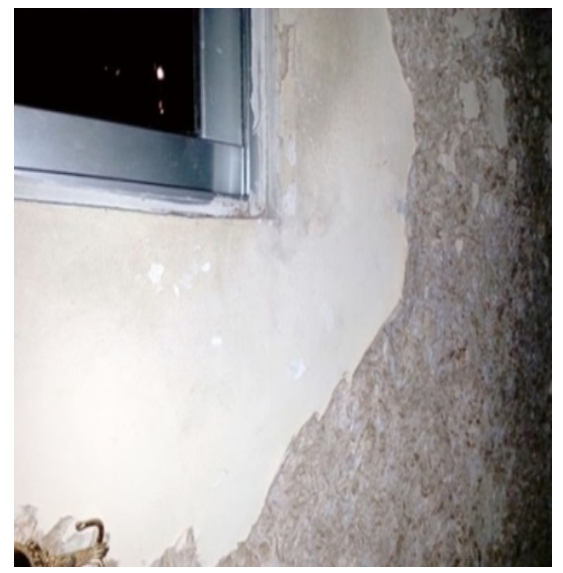

Figure 4: The Japanese plaster (teena yabaneyya) used by a low-income household. (Source: Younis, 2015, unpublished.)

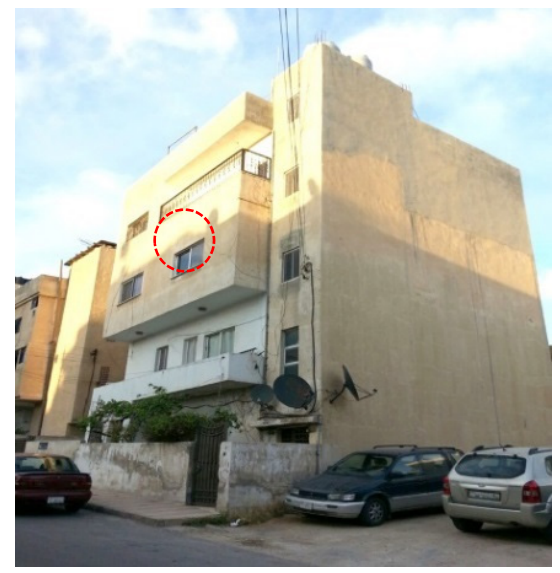

Figure 5: The location of the window in the building. (Source: Younis, 2015, unpublished.)

Comparatively, dominancy of this type of construction material coincides with the findings of Younis et al. [12], who in their analysis of the data collected from DoS concluded that the most used construction material of low and middle income apartments in urban Amman was the concrete hollow blocks. Also, the two results coincide with Jaber's claim as discussed above in Section 2.1 about the very tiny percentage of available wall insulated dwellings in Jordan. According to El Hanandeh [22], the U-value of this type of wall is $2.38 \mathrm{~W} / \mathrm{m}^{2} \mathrm{~K}$, which largely exceeds the optimum range (recommended by Ouahrani [23]), required for the roofs and walls of apartments in Amman, i.e. $0.50-0.70 \mathrm{~W} / \mathrm{m}^{2} \mathrm{~K}$.

Accordingly, it could be claimed that such apartments are thermally inefficient and this type of envelope would provide an ideal environment for the growth of fungus and mould. For instance, the appearance of fungi areas could be explained partially by the low ventilation rate. At the end of the day, this would render such apartments as thermally uncomfortable and may imply a lot of health hazards and accidents, given the inevitable emissions of pollutants, such as carbon dioxide and monoxide. 


\section{Conclusions}

We have investigated the use of heating devices in low-middle income apartments in urban Amman and the health implications associated with their usage. A survey was conducted with a representative sample of 106 households across the five subdistricts of urban Amman in winter 2015. Results have shown that around 39 percent and 89 percent of surveyed households used kerosene and LPG stoves, respectively, to heat their apartments, with almost 65 percent of total using more than one heating device as a back-up. Furthermore, findings revealed that about 50 percent of the surveyed households suffered from different health problems (e.g. asthma) which were associated with the different types of stoves used. Finally, it was also found that around 75 percent of the total surveyed apartments had a thermally poor external envelope with high U-value.

A literature review has highlighted that indoor pollutants and carbon emissions produced by the combustion of such petroleum fuels may have serious health and environmental implications. The review has also shown that the external envelopes of residential stock in Jordan are thermally inefficient. Finally, unless energy efficient measures are applied to those existing apartments, then health implications and an increase of GHG emissions by 2018, may be inevitable.

Given the aforementioned discussions, this paper would highly recommend low-cost/affordable retrofit packages for the low-middle income apartments to improve human thermal comfort and reduce GHG emissions. Eventually, this may result in providing a healthy indoor environment and enhancing the inhabitants' quality of living. In addition to this urgent call, it would be highly beneficial to raise the awareness of those households towards the proper and safe use of heating stoves inside their apartments.

\section{Acknowledgment}

The authors would like to express their great appreciation towards the surveyed households for their participation, providing a vital contribution to this paper, which is part of ongoing $\mathrm{PhD}$ research.

\section{References}

[1] Ministry of Environment and the United Nations Development Programme, Jordan, Jordan's second national communication to the United Nations Framework Convention on Climate Change (UNFCCC). Department of the National Library: the Hashemite Kingdom of Jordan, 2009.

[2] Alkurdi, N., Alshboul, A. \& Abu Ghanimeh, A., Poverty and comfort in modern residential apartments in developing countries: A case from Jordan. Proceedings of the 3rd International Conference on Construction in Developing Countries (ICCIDC-III), Advancing Civil, Architectural and Construction Engineering and Management, Bangkok, Thailand, 2012.

[3] United Nations Development Programme (UNDP), Jordan poverty reduction strategy: Final report, The Government of Jordan, 2013. 
[4] Jaber, J.O., Jaber, Q.M., Sawalha, S.A. \& Mohsen, M.S., Evaluation of conventional and renewable energy sources for space heating in the household sector. Renewable and Sustainable Energy Reviews, 12(1), pp. 278-289, 2008.

[5] Directorate of Planning \& Department of Statistics and Information, Energy consumption in domestic sector survey-methodology and results description. Ministry of Energy and Mineral Resources: the Hashemite Kingdom of Jordan, 1997. (In Arabic.)

[6] Jaber, J.O., Prospects of energy savings in residential space heating. Energy and Buildings, 34(4), pp. 311-319, 2002.

[7] Al-Ghandoor, A., Jaber, J.O., Al-Hinti, I. \& Mansour, I.M., Residential past and future energy consumption: Potential savings and environmental impact. Renewable and Sustainable Energy Reviews, 13(6-7), pp. 12621274, 2009.

[8] Johansson, E., Ouahrani, D., Al-Asir, H., Awadallah, T., Blomsterberg, A., Hakansson, H., Hellstrom, B. \& Kvist, H., Climate conscious architecture and urban design in Jordan-towards energy efficient buildings and improved urban microclimate. Report No. 12, Housing Development \& Management: Lund, Sweden, 2009.

[9] United Nations, United Nations development assistance framework 20132017.

[10] Department of Statistics, Jordan in Figures. The Hashemite Kingdom of Jordan, 2013.

[11] The Earth Institute of Columbia University, Background document for the national poverty reduction strategy. The Hashemite Kingdom of Jordan, 2012.

[12] Younis, A., Taki, A. \& Bhattacharyya, S., Low-middle income apartments in urban Amman/Jordan: Energy challenges and motivations. Proceedings of the 2nd International Conference on Architecture, Structure and Civil Engineering (ICASCE'16), London, UK, pp. 120-126, 2016.

[13] Al-Azhari, W. \& Al-Najjar, S., Challenges and opportunities presented by Amman's land topography on sustainable buildings. Proceedings of the 3rd International Conference on Construction in Developing Countries (ICCIDC-III), Advancing Civil, Architectural and Construction Engineering and Management, Bangkok, Thailand, 2012.

[14] ECODIT, Marketing Research Organization (MRO) \& USAID, KAP household-baseline survey: Public action for water, energy and environment project - final report. Report No. EPP-I-05-06-00010-00, 2010.

[15] Jaber, J.O., Probert, S.D. \& Badr, O., Energy and environmental issues for Jordan. Applied Energy, 57(1), pp. 45-101, 1997.

[16] Ghanem, H., Belhai, F., George, M., Comier, J., Beides, M., Berq, V.D. \& Esen, F., Program document for a proposed loan in the amount of $\$ 250$ million to the Hashemite Kingdom of Jordan for a first programmatic energy and water sector reforms development policy loan. Report No. 94786-JO, International Bank for Reconstruction and Development: the Hashemite Kingdom of Jordan, 2015. 
[17] Attia, S. \& Zawaydeh, S., Strategic decision making for zero energy buildings in Jordan. Proceedings of the 1st International Conference on Energy \& Indoor Environment for Hot Climates, Doha, 2014.

[18] Gomzi, M. \& Bobic, J., Sick building syndrome: Do we live and work in unhealthy environment? Periodicum Biologorum, 111(1), pp. 79-84, 2009.

[19] Jaber, J.O. \& Probert, S.D., Energy demand, poverty and the urban environment in Jordan. Applied Energy, 68(2), pp. 119-134, 2001.

[20] Al Momani, H.M. \& Ali, H.H., Sick building syndrome in apartment buildings in Jordan. Jordan Journal of Civil Engineering, 2(4), pp. 391403, 2008.

[21] Bierwirth, P.N., Effects of rising carbon dioxide levels on human health via breathing toxicity: A critical issue that remains unapprehended, 2016. DOI: 10.13140/RG.2.1.3297.9368.

http://grapevine.com.au/ pbierwirth/co2toxicity_climate_blog.html.

[22] El Hanandeh, A., Environmental assessment of popular single-family house construction alternatives in Jordan. Building and Environment, 92, pp. 192199, 2015.

[23] Ouahrani, D., Towards energy efficient buildings in Amman, Jordan: Defining thermal requirements by mean of thermal simulations. Proceedings of the 44th Annual Conference of the Architectural Science Association (ANZAScA), Unitec Institute of Technology, Auckland, New Zealand, 2010. 